\title{
An Analysis on Modes of Scientific and TechnologicaInformation Integration Services in the E- environment
}

\author{
Ping Wang, Weidong Zhang, Ye Yuan, Xueyan Song \\ School of Management, Jilin University, Chang chun, China \\ wdzhang@jlu.edu.cn
}

\begin{abstract}
During the combination of knowledge and capital, science and technology intermediaries are demanded to provide information integration services. Science and technology intermediaries play an important role in quickening the commercialization of research findings, developing new and high technology industry, and promoting regional scientific and technological innovations. With the influences of the computer age on science and technology information services as the starting point, the thesis makes a largescale survey of websites of state and provincial comprehensive science and technology intermediaries, and based on this, the overall framework of scientific and technological information integration services under the Eenvironment is established, and furthermore, the functions and structures of different subsystems are systemically analyzed in the modes of scientific and technological information integration services.
\end{abstract}

\section{Introduction}

The arrival of the era of network poses a great convenience for the information services of science and technology intermediaries. As online scientific and technological information services break down the time and space limitations, any innovation subject can access information quickly. The network dissemination of scientific and technological information makes it more transparent, and thus quickens the fusion of knowledge with capital. Integration services of scientific and technological information in the network environment have become a reality. Integrated services effectively integrate all elements of information resources organically into an overall dynamic process, which is displayed to its users through the network, and enable users to quickly access services based on the theme of 'one-

Please use the following format when ciling this chapter:

Wang, P., Zhang, W., Yuan, Y., Song, X., 2007, in IFIP International Federation for Information Processing, Volume 252, Integration and Innovation Orient to E-Socicty Volumc 2, cds. Wang, W., (Boston: Springer). pp. 184-192. 
stop', which is very convenient for users to make personalized options and professional use.

\section{Statistical analysis of websites of science and technology intermediaries}

2003 is the year of 'construction of science and technology intermediaries' prescribed by the Ministry of Science and Technology of China. [1] Science and technology intermediary websites have developed rapidly. Science and technology intermediary, as an aggregate concept, can be roughly divided into the following 12 categories: Productivity promotion center, Science and technology entrepreneurial service centers, Scientific and technological information agencies, Science and technology assessment and advisory bodies, Technology transactions, Venture investment and financing services, Agricultural extension services, Tech services sector, Professional agent, Trade or professional associations, Science and technology talents service providers and Management consulting agencies. [2]Due to its numerousness and diversity, it is very difficult to carry out disaggregated statistical analysis on these websites, and therefore, since the beginning of 2007, the authors of this thesis have only selected science and technology information agencies and make a sample analysis, by means of visiting websites. The samples include the national and provincial scientific and technical information network platforms, in which 75 national science and technology information websites are surveyed, and 136 provincial ones are involved. The provincial science and technology information network platforms cover all the mainland provinces, autonomous regions and municipalities, and the average number of samples of each province is 3 to 5 .

\subsection{Analysis of Problems}

In general, the overall quality of Chinese scientific and technological information website construction is of sorts, which is embodied in the following aspects:

(1)Lack of standardization resulted from the too large number of websites.

(2) Loss of characteristics resulted from diverse columns.

(3) Redundant construction.

(4) Unsound mechanism of scientific and technological information dissemination.

(5) Stereotyped service means.

(6) Low degree of specialization, personalization, and intellectualization of services.

\subsection{Solutions}

Based on the above analysis of problems, the authors of this thesis think that it is very necessary to construct a scientific and technological information service mode which highly integrates resources, technologies and services. Modes of scientific and technological information integration services in e-environment are expected to reach the following goals. 


\subsubsection{Integration of resources --- optimization of information dissemination.}

The problem of resources allocation facing scientific and technological information websites should be solved from both macro and micro perspectives. As a whole, governments should concentrate manpower and material and financial resources to build comprehensive scientific and technological information portals, integrate public scientific and technological information databases, commercial scientific and technological information databases, databases of patents, databases of research findings and so on, and invest more in information organization technology and intelligent retrieval technology. Meanwhile, scientific and technological information websites of other regions and in other industries can focus on construction of distinctive information databases, which can share information interactively with platform of scientific and technological information portals. On the basis of such macro-view of platform, scientific and technological information services tend to be improved and optimized. At the micro level, scientific and technological information websites should unite columns and stress features by collecting information from enterprises, research institutes, universities and governments, then organizing them carefully and publishing them timely.

2.2.2 Integration of technologies --- intellectualization of information services. The main trend of information services is rising of online services. Modern technologies like intelligent retrieval, personalized push and semantic web have been extensively used applied in information service field. When integration of information technologies is done, experts' intelligence factors should be taken into consideration. Online reference and consultation services, which combine information technologies with expert intelligence, will meet users' high-level demands effectively.

\subsubsection{Integration of services --- 'one-stop' trip.}

With abundant information resources, modernized information technologies, and diverse means of services, users' demands for information can be met sufficiently. With integration of a variety of service functions like navigation, intelligent retrieval, online reference and consultation, personalized services and link services, users can get access to information they need on one website timely and accurately.

\section{Modes of scientific and technological information integration services in the e-environment}

Scientific and technological information integration services are mainly reflected in two aspects: First, the integration of scientific and technological information resources is the foundation of providing effective services. Science and technology intermediaries need to integrate regional, trade or even global resources, including information of scientific research findings, patents, enterprise technology needs, talents and scientific and technological literature resources, to provide users with specialized services. Second, the integration of information services is not only integrated information resources services. The focus is no longer the provided information resources themselves, but has been shifted to specific problems the enterprise seeks to solve. Through information integration services, users are allowed 
to enjoy 'one-stop' information supply, to reach an overall solution, and eventually a blend of knowledge and capital will be realized, which will be transformed into economic benefits in reality. [3] The modes of scientific and technological information integration services need to be constructed on such basis.

\subsection{Overall framework of modes of science and technology information integration services}

The overall framework of modes of science and technology information integration services is designed on the basis of two layers: information layer and service layer (see figure 1). Based on database of science and technology information, database of users and enterprises information, and database of policies and regulations, information layer mainly deals with several issues such as organization, dissemination, and retrieval of information resources, and integration of users information; on the service layer, services which are mainly aimed at specific users are integrated, including online reference and consultation services, personalized services, professional training services, agency services, etc.

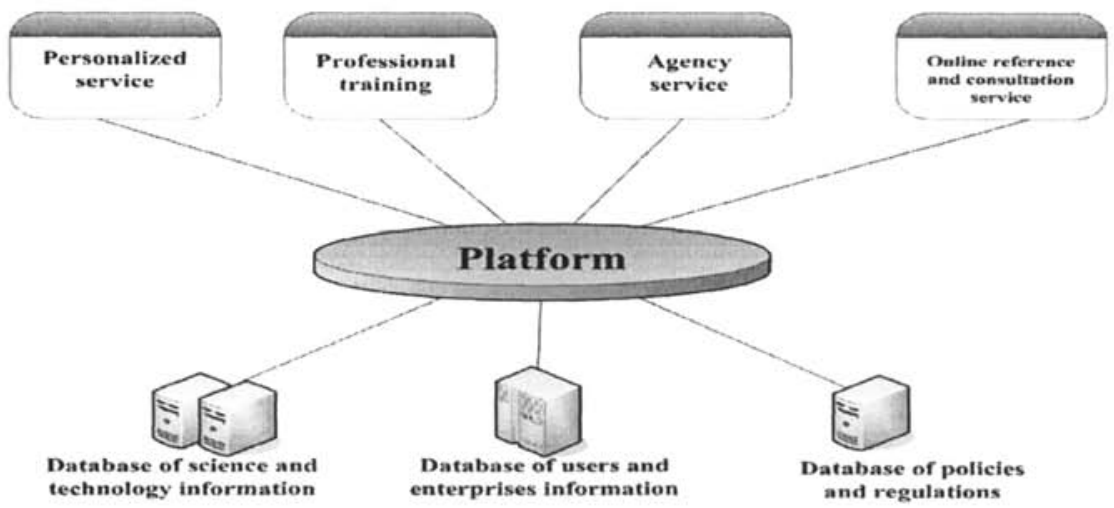

Figure 1. overall framework of science and technology information integration services

\subsection{Function modules of modes of science and technology information integration services}

\subsubsection{Module of science and technology information dissemination}

Science and technology information dissemination system is an important indicator which is used to examine integration services of science and technology intermediaries from the perspective of resources supply, and is also the foundation of science and technology information services. As to the demands of specific users, science and technology intermediaries collect, organize, and integrate information, and disseminate it on internet platform, so that the demand of different innovation 
subjects is met. Science and technology information resources dissemination system is designed mainly on the following four layers (see figure 2): Enterprise Information Dissemination Platform, Science and Technology Information Dissemination Platform, Professional and Technical Data Release Platform, and Policies and Regulations Dissemination Platform.

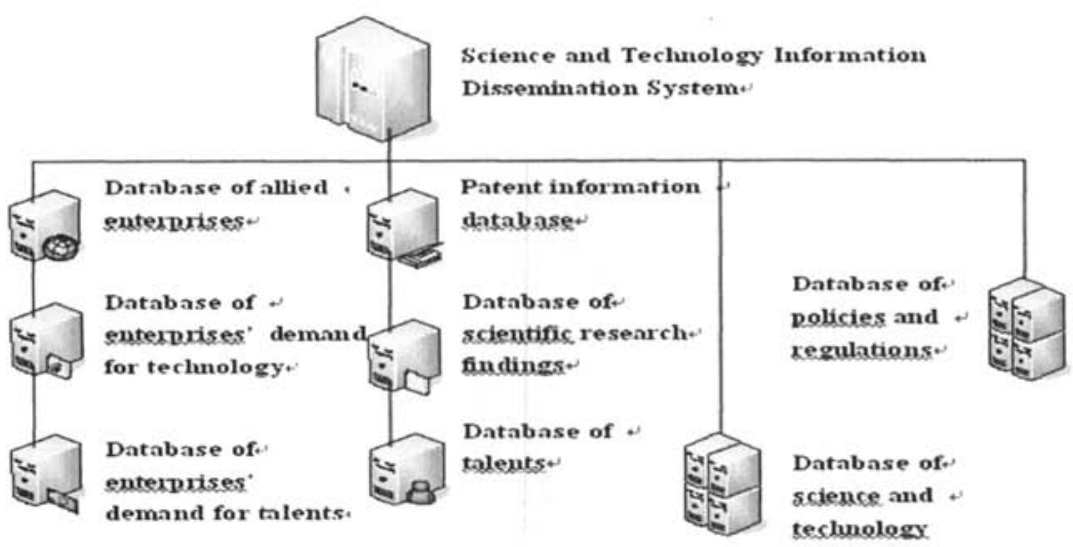

Figure 2. structure of modules of science and technology information resources dissemination

\subsubsection{Module of Cross-database Integrated Retrieval}

Cross-database integrated retrieval, based on various databases set up in science and technology information resources dissemination system, integrates many databases of scientific and technological information effectively, as a result of which, users can accomplish retrieval of all the databases available under only one interface. Users do not need to $\log$ in and retrieve different databases one after another, and furthermore, with simple and swift the process of retrieval, and unified research interface format, the burdens on users are reduced. The integration of cross-database retrieval is also embodied by the realization of functions like links between cross-database citations, links between knowledge elements, knowledge hubs, intellectual research, etc. Hence, the use efficiency is improved. [4]

Retrieval interface is supposed to design navigation systems for users. Navigation database is set up through collection, analysis, selection, organization, and description of various scientific and technological information resources, which enables a user to be aware of his or her location, and accurately select database to get access to information, and in this way, the user is unlikely to get lost (see figure 3). 


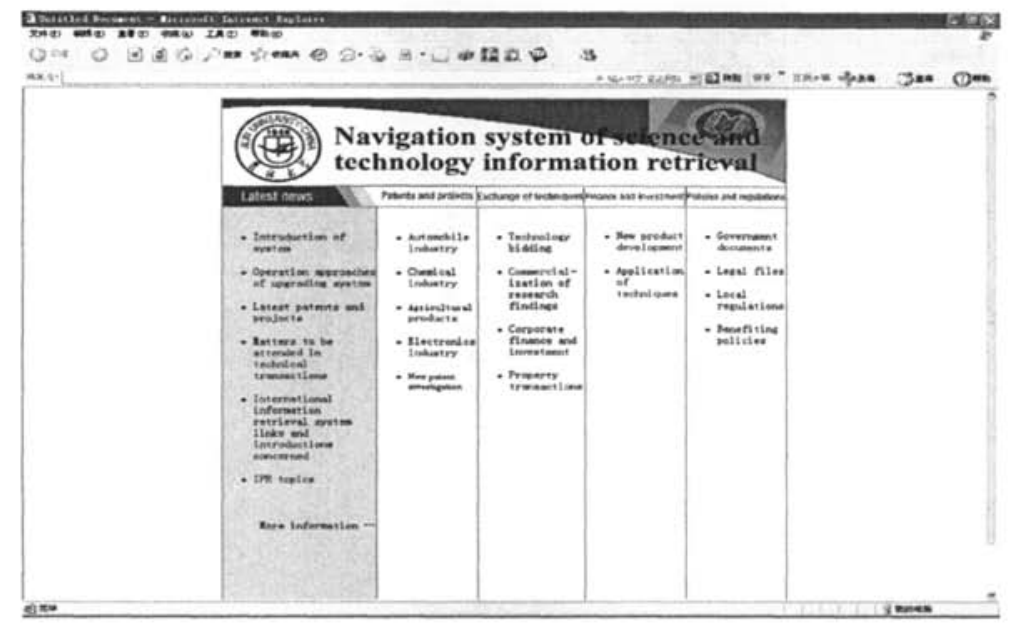

Figure 3 navigation function of science and technology information integration

\subsubsection{Module of Online Reference and Consultation Services}

Online reference and consultation services system of scientific and technological information is digital form which has the traditional expert advisory services as foundation. It combines traditional forms of reference, and uses the e-commerce online customer service experiences for reference. It meets users' different demands for information recurring to reference desk, telephone, FAQ databases, e-mail, web forms, bulletin boards or discussion groups, online chat, a common browser, internet-advisory services, network meetings of advisory services, expert advisory services, and cooperation in the digital reference services. [5] (see figure 4)

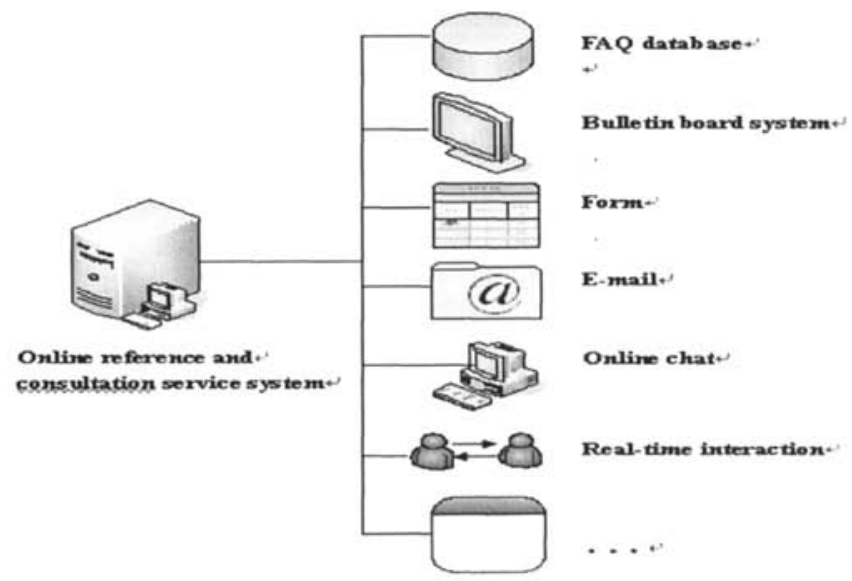

Figure 4. framework of online reference and consultation service system 


\subsubsection{Module of Personalized Services}

Personalized services system is based on specific demands of specific users. Personalized services system of scientific and technological information is mainly targeted at technology-based small and medium-sized enterprises which have a big demand for technology. Customization and push of information are considered the core of personalized service system. [6] Customization is one of the effective ways of understanding users' demand, through which, personalized information about users can be obtained, and users' demand can be comprehended, and more accurate services will be offered to users. The so-called push technology refers to a kind of information sending technology, which is achieved by tracking users' network activities, extracting, tracing and analyzing users' personal interests and hobbies, forming a user model, and then referring to users' customization. Push services also regularly or irregularly take the initiative to 'push' users special information they are interested in. Construction of user model is a critical component of personalized information service system. User model is mainly realized through push server which sets up model of user information by guiding users and extracting and analyzing users' interests. (see figure 5)

(1) Visitors to information integration platform of a science and technology intermediary have to land user interface, and fill in the corresponding registration information (new visitors). User interface offers options reflecting user's basic features, such as age, occupation, education and personal profiles, and such options serve as the basic elements of database of users.

(2) With the entry of user basic information into database of users, user model is set up. Analyses are made on basic elements of users and tracks in which users get access to archives resources, then the most basic characteristics of user demand are extracted, and therefore, foundation of realizing personalized services has been laid.

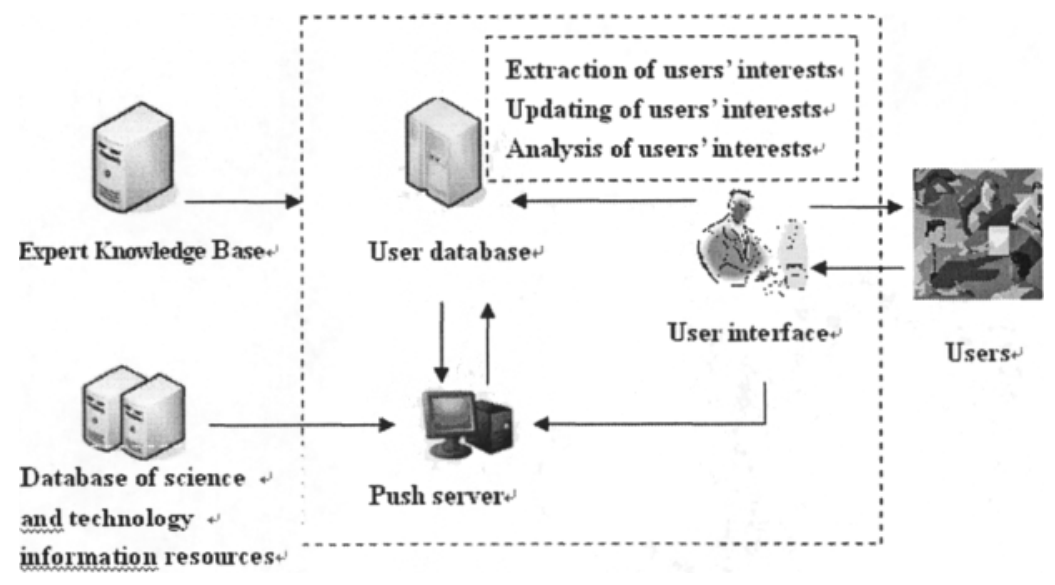

Figure 5. flow of personalized services of science and technology information 
(3) A user submits demand to intellectual retrieval system, the demand enter into push server which makes the initial matching search according to the user's retrieval order, but the information obtained at this moment cannot be provided to the user. Simultaneously, push server enters into database of users to research for the user's historical documents, and then put the user's descriptive information in user model to analyze and filter the user's interests.

(4) Comparison is made between user interests and the information obtained initially and than some content is extracted, so the ultimate retrieval content is fixed and is pushed to users. Meanwhile, the user's application of this time will be stored in database of users. Push server will periodically identify the latest information which a user is interested in, and push technological information catalogues irregularly through e-mail, nurturing the stable user groups. When providing users with information services, expert intellectual knowledge database also plays a key role.[7]

\subsubsection{Other Services}

(1) Convergence of information about the latest developments of science and technology. Science and technology information integration service system possesses a special retrieval system which, with the help of human work, collects and converges the latest technological developments, news and policies, after that, releases them on the websites of science and technology intermediaries quickly and timely.[8]

(2) Professional training services. Professional training services may take the form of training class or online training, and training content includes professional business administration, use of database, or examination of scientific and technological information.

(3) Agency services. Science and technology information integration service system submits online forms. Users can entrust science and technology intermediaries with such operations as investigating new scientific developments and downloading scientific and technological information by filling in an online agency standing order.

\section{Conclusions and Outlook}

Since China's science and technology intermediary service system is still in a stage of development, and the overall level of information integration services is not high enough, modes of science and technology information integration services constructed in the thesis are just a framework which is feasible in theory. Many problems remain to be solved in practice.

(1) Of government support. Governments should offer greater support in terms of policies, funds, and technology, and construct a perfect and efficient information service platform in collaboration with enterprises, universities, research institutes and science and technology intermediaries.

(2) Of intellectual property rights. authorization of database constructors has to be obtained when integration of different databases is conducted, and besides, rational utilization is preferred and malicious download and abuse should be avoided. 
(3) Of economy. investment income and interest is a problem which future science and technology intermediaries, enterprises, research institutes, universities and governments will have to face.

(4) Of technology. It remains to be further studied how to integrate different types of information into one system.

\section{References}

1. People's Republic of China Ministry of Science and Technology, 2003: Year of 'Construction of Science and Technology Intermediaries'

(Apr.21,2007)http://www.most.gov.cn/kjjr/jyj//200303/L20030321_9568.htm.

2.Questionnaire of Science and Technology Intermediaries,

(Feb.25,2007)http://www.Ininfo.gov.cn/.

3 Qiang.B, H.Y. Shi, Research on Modes of Information Integration Services [J], Library and Information Service, 2004(9).P30-33.

4.web of CNKI,(Apr.25,2007);http://www.cnki.net/index.htm.

5.IFLA Digital Reference Guide .(Apr.25,2007).

http://zsdh.library.sh.cn/vrdguide.htm.

6.Y.L. Hao.Push Technology--The Realzation of Personalized Information Service on Network. Journal of Information 2002（10）.P55.

7 W.D. .Zhang, P. Wang, Study on Personalized Service Modes Driven by Archive User, Archives Science Bulletin.2007 (2) P85.

8. Y. et.al. Construction Ideas of Patent Information Integration Platform, Information Science: Theory and Application.2007 (1) P91. 